\title{
Mining Prognostic Significance of MEG3 in Human Breast Cancer Using Bioinformatics Analysis
}

\author{
Xiangrong Cui ${ }^{a, b, c}$ Qin Yij ${ }^{a, b, c}$ Xuan Jing ${ }^{e}$ Yue Huang ${ }^{a, b, c}$ Jie Tian ${ }^{d}$ \\ Chunlan Long ${ }^{a, b, c}$ Zhongping Xiang ${ }^{a, b, c}$ Jianping Liu ${ }^{f} \quad$ Chunmin Zhang ${ }^{g}$ \\ Bin Tan ${ }^{a, b, c}$ Yasha Li ${ }^{a, b, c}$ Jing Zhu $u^{a, b, c}$
}

aPediatric Research Institute, Children's Hospital of Chongqing Medical University, Ministry of Education Key Laboratory of Child Development and Disorders, Chongqing, ${ }^{b}$ China International Science and Technology Cooperation Base of Child Development and Critical Disorders, Chongqing, 'Chongqing Key Laboratory of Pediatrics, Chongqing, ${ }^{\mathrm{d} C a r d i o v a s c u l a r ~ D e p a r t m e n t ~(I n t e r n a l ~ M e d i c i n e), ~ C h i l d r e n ' s ~}$ Hospital of Chongqing Medical University, Chongqing eClinical Laboratory, Shanxi Province People's Hospital, Shanxi, ${ }^{f}$ Clinical Laboratory, The First Affiliated Hospital of Nanchang University, Jiangxi, ${ }^{9}$ Clinical Laboratory, The Tumor Hospital of Chongqing, Chongqing, China

\section{Key Words}

Long non-coding RNAs $•$ MEG3 $•$ Breast carcinoma $•$ Prognosis

\begin{abstract}
Background/Aims: Maternally expressed gene 3 (MEG3) is an imprinted gene with maternal expression, which may function as a tumor suppressor by inhibiting angiogenesis. To identify the prognostic value of MEG3 in breast cancer, systematic analysis was performed in this study. Methods: To evaluate gene alteration during breast carcinogenesis, we explored MEG3 expression using the Serial Analysis of Gene Expression Genie suite and Oncomine analysis. The prognostic roles of MEG3 in breast cancer were investigated using the PrognoScan database. The heat map and methylation status of MEG3 were determined using the UCSC Genome Browser. Results: We found that MEG3 was more frequently downregulated in breast cancer than in normal tissues and this correlated with prognosis. However, estrogen receptor and progesterone receptor status were found to be positively correlated with MEG3 expression. Conversely, basal-like status, triple-negative breast cancer status, and Scarff Bloom \& Richardson grade criterion were negatively correlated with MEG3 expression. Following data mining in multiple big data databases, we confirmed a positive correlation between MEG3 and heparan sulfate proteoglycan 2 (HSPG2) expression in breast cancer tissues. Conclusion: MEG3 could be adopted as a marker to predict the prognosis of breast cancer with HSPG2. However, large-scale and comprehensive research is needed to clarify our results.

X. Cui, Q. Yi and X. Jing contributed equally to this work.

\begin{tabular}{ll}
\hline Jing Zhu & Pediatric Research Institute, Children's Hospital of Chongqing Medical University \\
& Chongqing 400014 (China)
\end{tabular}

E-Mail 412232858@qq.com
\end{abstract}




\section{Cellular Physiology Cell Physiol Biochem 2018;50:41-51 \begin{tabular}{l|l} 
and Biochemistry Published online: 3 October 2018 & $\begin{array}{l}\text { D } 2018 \text { The Author(s). Published by S. Karger AG, Basel } \\
\text { www.karger.com/cpb }\end{array}$
\end{tabular}}

Cui et al.: Mining Prognostic Significance of MEG3 in Human Breast Cancer

\section{Introduction}

Breast cancer remains a leading cause of cancer-related death in women [1-3]. Despite increased screening and improved diagnosis and treatment of breast cancer, prognosis remains poor [4-6]. Therefore, the development of more sensitive and specific biomarkers for the prognosis of patients with breast cancer is urgently needed.

Long non-coding RNAs (lncRNAs) are commonly defined as non-protein coding transcripts longer than 200 nucleotides, many of which are emerging as a critical class of regulatory molecules through a variety of mechanisms involved in regulating fundamental biological processes [7-9]. In tumors, abnormal expression of IncRNAs contributes to the development and progression of cancer by influencing proliferation, apoptosis, autophagy, metastasis, self-renewal, and survival via epigenetic, transcriptional, and post-transcriptional gene regulatory mechanisms [10-12]. Furthermore, aberrant expression of lncRNAs can be detected in circulating cancer cells and in the serum and urine of cancer patients, which suggests that IncRNAs may serve as an effective biomarker for cancer detection and prognosis $[13,14]$.

Maternally expressed gene 3 (MEG3) is the first lncRNA that has been shown to function as a tumor suppressor and inhibit cell proliferation in numerous human cancer cell lines, and it is expressed in many normal human tissues [15-17]. Loss of MEG3 expression has been identified in many human tumors, including cervical cancer [18], retinoblastoma [19], ovarian carcinoma [20], gastric cancer [21], germ cell tumor [22], and squamous cell carcinoma [23], and such loss is indicative of poor prognosis. MEG3 has also been demonstrated to inhibit cell growth in gliomas by targeting miR-93 and inactivating the PI3K/AKT pathway [24]. Moreover, upregulation of MEG3 can induce autophagy to inhibit tumorigenesis and progression of epithelial ovarian carcinoma by regulating ATG3 activity [20]. Taken together, these findings suggest that MEG3 may not only act as a potential therapeutic target, but also as a novel predictive biomarker of progression and prognosis of cancer.

In this study, we evaluated the significance of MEG3 expression in human breast cancer by using bioinformatics. The study was performed to comprehensively analyze the expression pattern, potential function, and distinct prognostic effect of MEG3 in breast cancer by pooling and analyzing all currently available data.

\section{Materials and Methods}

Serial analysis of gene expression (SAGE)

All available published SAGE data were utilized for analysis of lncRNA MEG3 gene expression in normal and malignant human tissues. Digital lncRNA MEG3 gene expression profiles were analyzed and displayed using the SAGE Anatomic Viewer (hppt://www.ncbi.nlm.nih.gov/SAGE/).

\section{Oncomine database analysis}

The Oncomine database (http://www.oncomine.org) is a web-based data mining platform that incorporates 264 independent datasets and aims to collect, standardize, analyze, and deliver transcriptomic cancer data for biomedical research [25]. LncRNA MEG3 mRNA levels in breast cancer tissues were compared with their matched normal tissues by using online Oncomine analysis tools. The threshold used to obtain the most significant probes of the lncRNA MEG3 for each microarray data included a two-fold difference in expression between cancers and normal tissues with a p-value of less than $1 \times 10^{4}$. Genes co-expressed with MEG3 were analyzed.

UCSC cancer genomics browser analysis

The heat map and correlation between IncRNA MEG3 and HSPG2 in the same patient cohort were verified and analyzed by data mining in TCGA-GBM using the UCSC Xena browser (http://xena.ucsc.edu/). Subsequently, the methylation status of IncRNA MEG3 was also examined using the UCSC Xena browser [26-28]. 


\section{Cellular Physiology Cell Physiol Biochem 2018;50:41-51

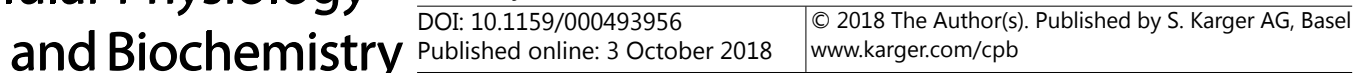

Breast cancer gene-expression miner 4.1

Breast Cancer Gene-Expression Miner v4.1 (bcGenExMiner v4.1), a statistical mining tool of published annotated genomic data, was utilized to assess lncRNA MEG3 expression in breast cancer [29, 30]. Correlations of lncRNA MEG3 and HSPG2 were assessed using the bc-GenExMiner v4.1 correlation module.

\section{PrognoScan}

The PrognoScan online database (http://www.prognoscan.org/) provides a powerful platform for assessing the biological relationships between gene expression and prognosis in cancer patients [31]. PrognoScan automatically calculates hazard ratios, 95\% confidence intervals, and Cox P-values according to the mRNA level (high or low) of a given gene.

\section{Results}

LncRNA MEG3 transcript expression and methylation status in human breast cancer

As a long non-coding RNA, the expression profile of MEG3 was identified using the SAGE Digital Gene Expression Display. Our analysis revealed that IncRNA MEG3 expression was lower in brain, breast, kidney, peritoneum, prostate, and lymph node tissues compared with their matched normal tissues (Fig. 1). We also analyzed the expression profile of MEG3 by Oncomine database analysis. Lower expression of MEG3 was identified in human cancers, including hematological malignancies and solid tumors (Fig. 2). Oncomine analysis of cancer vs. normal samples revealed that lncRNA MEG3 expression was significantly lower in invasive breast carcinoma, invasive lobular breast carcinoma, invasive ductal breast carcinoma, male breast carcinoma, invasive ductal and lobular carcinoma, breast carcinoma, medullary breast carcinoma, mucinous breast carcinoma, ductal breast carcinoma in situ, and tubular breast carcinoma (Table 1, Fig. 3) [32, 33]. Comparing the MEG3 expression heatmap and DNA methylation status revealed that its expression might be negatively related with some $\mathrm{CpG}$ sites (blank frame) (Fig. 4A). By comparing MEG3 expression in different DNA methylation clusters, we also confirmed that MEG3 expression gradually decreased with increasing DNA methylation (Fig. 4B).

Genetic alternations of MEG3 and clinicopathological parameters in breast cancer patients

In bc-GenExMiner, Welch's t-test was performed to compare the transcription levels of MEG3 among groups of patients, based on different clinicopathological parameters (Table 2). Regarding age, no significant differences were found between the $\leq 51$ years and >

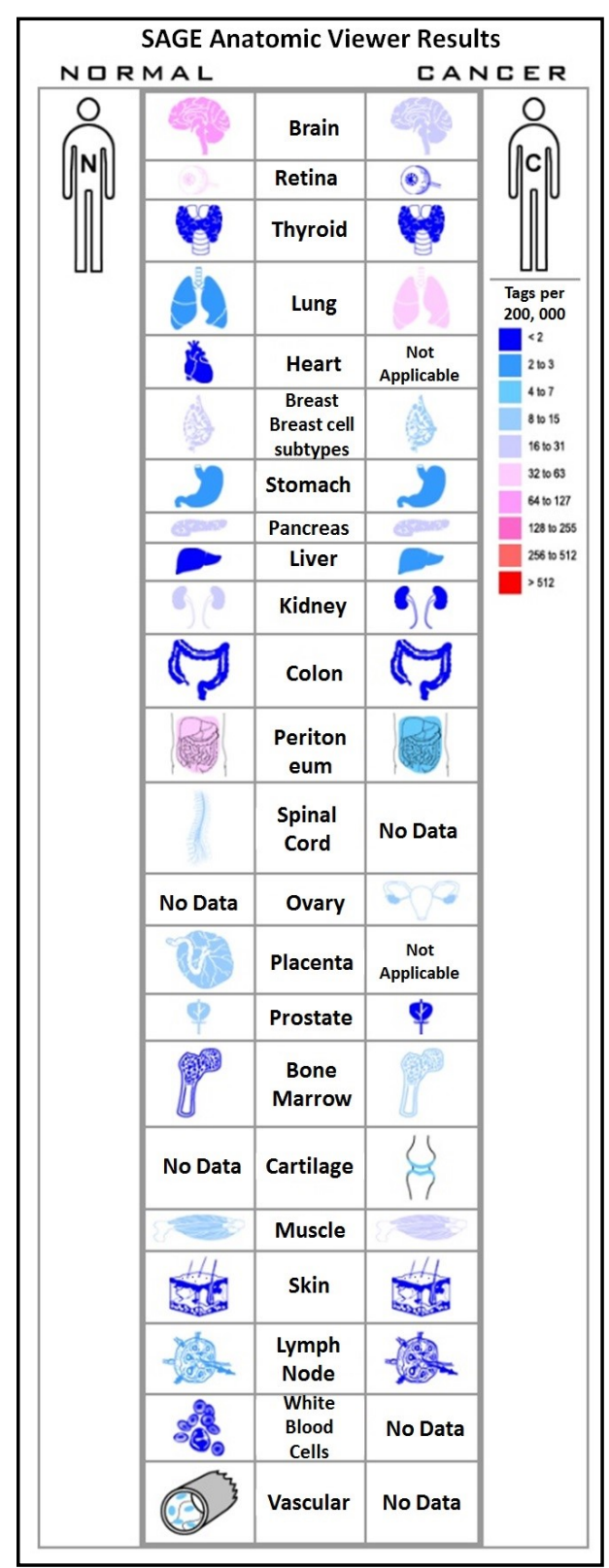

Fig. 1. Expression profile for MEG3 in human breast cancer using the SAGE digital gene expression displayer. 


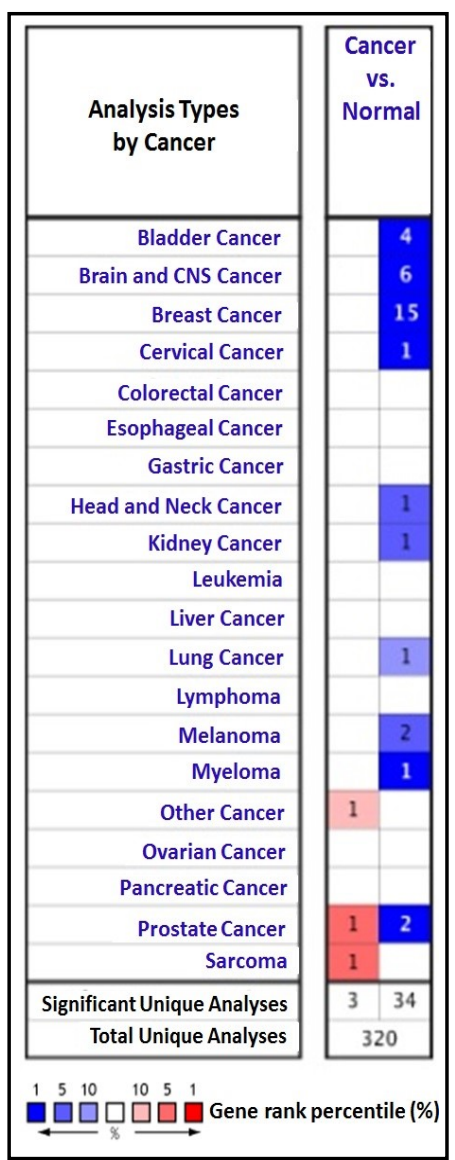

Fig. 2. Expression of MEG3 in different types of cancers. This graphic generated by Oncomine indicates the numbers of datasets with statistically significant $(p<0.01)$ mRNA over-expression (red) or down-expression (blue) of MEG3 (different types of cancer vs. corresponding normal tissue). The threshold was designed with the following parameters: p-value of $1 \mathrm{E}-4$, fold change of 2 , and gene ranking of $10 \%$.
Table 1. The significant changes of MEG3 expression in transcription level between different types of breast cancer and normal tissues (ONCOMINE database)

\begin{tabular}{|c|c|c|c|c|c|}
\hline Subtype of breast cancer & $\mathrm{p}$-value & $\begin{array}{c}\text { Fold } \\
\text { change }\end{array}$ & $\begin{array}{c}\text { Rank } \\
(\%)\end{array}$ & Sample & Reference \\
\hline Invasive Breast Carcinoma & $\begin{array}{c}7.06 \mathrm{E}- \\
14\end{array}$ & -4.726 & $1 \%$ & 158 & 21373875 \\
\hline Invasive Breast Carcinoma & $\begin{array}{l}2.00 \mathrm{E}- \\
30\end{array}$ & -5.759 & $1 \%$ & 137 & TCGA \\
\hline Invasive Lobular Breast Carcinoma & $\begin{array}{l}6.13 \mathrm{E}- \\
15\end{array}$ & -2.964 & $2 \%$ & 97 & TCGA \\
\hline Invasive Ductal Breast Carcinoma & $\begin{array}{l}1.38 \mathrm{E}- \\
36\end{array}$ & -5.874 & $2 \%$ & 440 & TCGA \\
\hline Male Breast Carcinoma & $4.02 \mathrm{E}-8$ & -5.369 & $2 \%$ & 64 & TCGA \\
\hline Invasive Ductal and Lobular Carcinoma & $1.09 \mathrm{E}-5$ & -3.108 & $3 \%$ & 64 & TCGA \\
\hline Invasive Ductal Breast Carcinoma & $\begin{array}{l}2.44 \mathrm{E}- \\
86\end{array}$ & -4.565 & $1 \%$ & 1700 & 22522925 \\
\hline $\begin{array}{l}\text { Invasive Ductal and Invasive Lobular Breast } \\
\text { Carcinoma }\end{array}$ & $\begin{array}{c}8.95 \mathrm{E}- \\
40\end{array}$ & -2.655 & $2 \%$ & 234 & 22522925 \\
\hline Invasive Lobular Breast Carcinoma & $\begin{array}{c}6.23 \mathrm{E}- \\
48\end{array}$ & -3.667 & $2 \%$ & 292 & 22522925 \\
\hline Breast Carcinoma & $\begin{array}{c}2.15 \mathrm{E}- \\
10\end{array}$ & -3.474 & $2 \%$ & 158 & 22522925 \\
\hline Medul lary Breast Carcinoma & $\begin{array}{l}2.07 \mathrm{E}- \\
20\end{array}$ & -3.221 & $2 \%$ & 176 & 22522925 \\
\hline Mucinous Breast Carcinoma & $\begin{array}{l}1.27 \mathrm{E}- \\
22\end{array}$ & -3.239 & $3 \%$ & 190 & 22522925 \\
\hline Invasive Breast Carcinoma & $1.51 \mathrm{E}-9$ & -2.802 & $3 \%$ & 165 & 22522925 \\
\hline Tubular Breast Carcinoma & $\begin{array}{l}5.81 \mathrm{E}- \\
29\end{array}$ & -3.708 & $4 \%$ & 211 & 22522925 \\
\hline Ductal Breast Carcinoma in Situ & $8.18 \mathrm{E}-5$ & -5.841 & $7 \%$ & 154 & 22522925 \\
\hline
\end{tabular}

51 years groups (Table 2). HER2 status and nodal status also showed no significant differences between positive and negative status (Table 2, Fig. 5). Estrogen receptor (ER) and progesterone receptor (PR) status were found to be positively correlated with MEG3 expression (Table 2, Fig. 5). Conversely, in breast cancer patients with negative basal-like status, expression of MEG3 was significantly increased compared with positive basal-like status (Table 2, Fig. 5). TNBC is a special type of breast cancer, with ER (-), PR (-), and HER2 $(-)$ type classifications. We found that expression of MEG3 was significantly upregulated in non-TNBC patients (Table 2, Fig. 5). In terms of the Scarff Bloom \& Richardson grade status (SBR) criterion, more advanced SBR grade was associated with lower MEG3 mRNA level (Fig. 5). The prognostic value of MEG3 expression was shown using the PrognoScan database, 


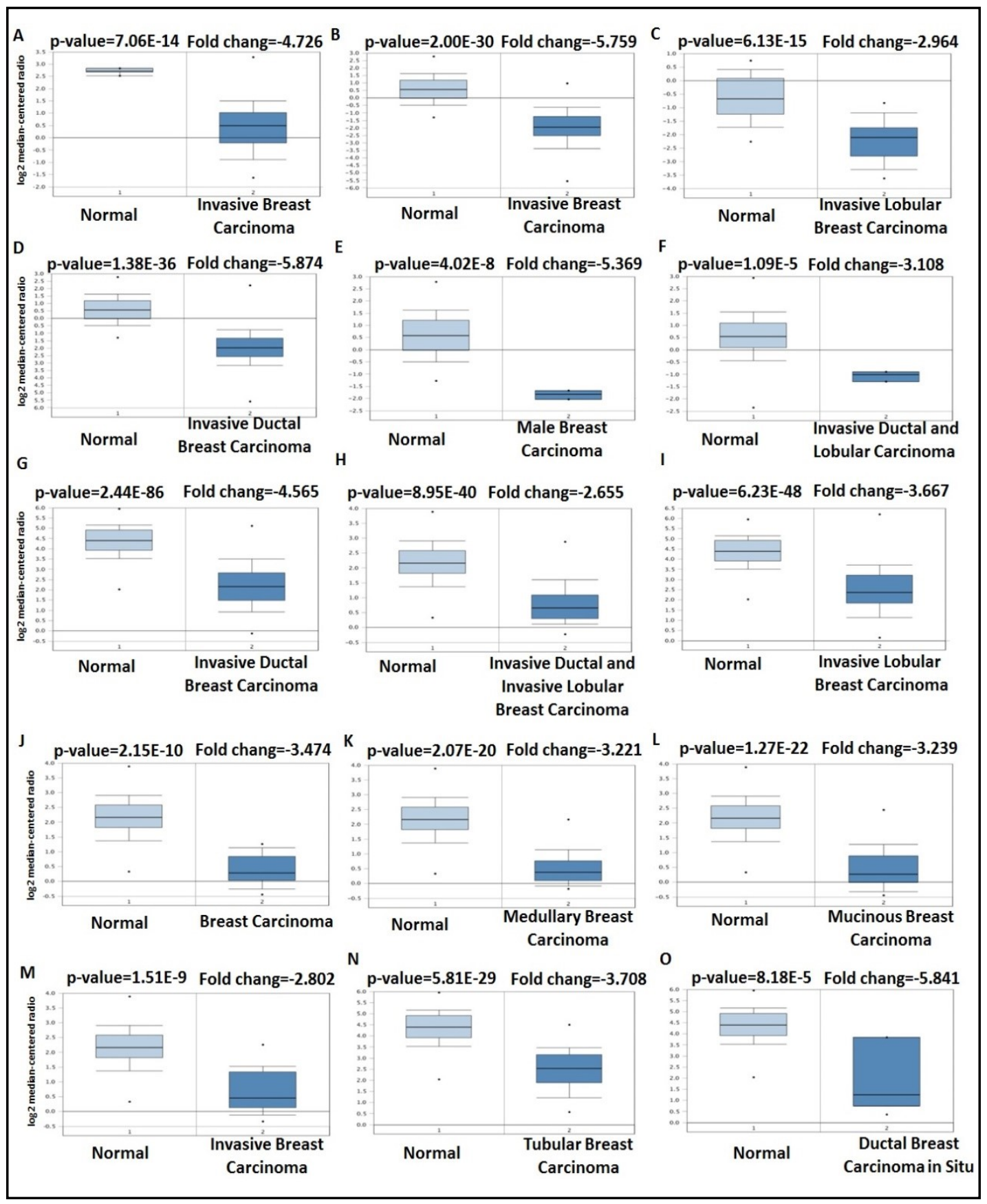

Fig. 3. MEG3 analysis in breast cancer (Oncomine database). Box plot comparing specific MEG3 expression in normal (left) and cancer tissue (right) generated from Oncomine database. Analysis is shown for invasive breast carcinoma, invasive lobular breast carcinoma, invasive ductal breast carcinoma, male breast carcinoma, invasive ductal and lobular carcinoma, breast carcinoma, medullary breast carcinoma, mucinous breast carcinoma, ductal breast carcinoma in situ, and tubular breast carcinoma. 


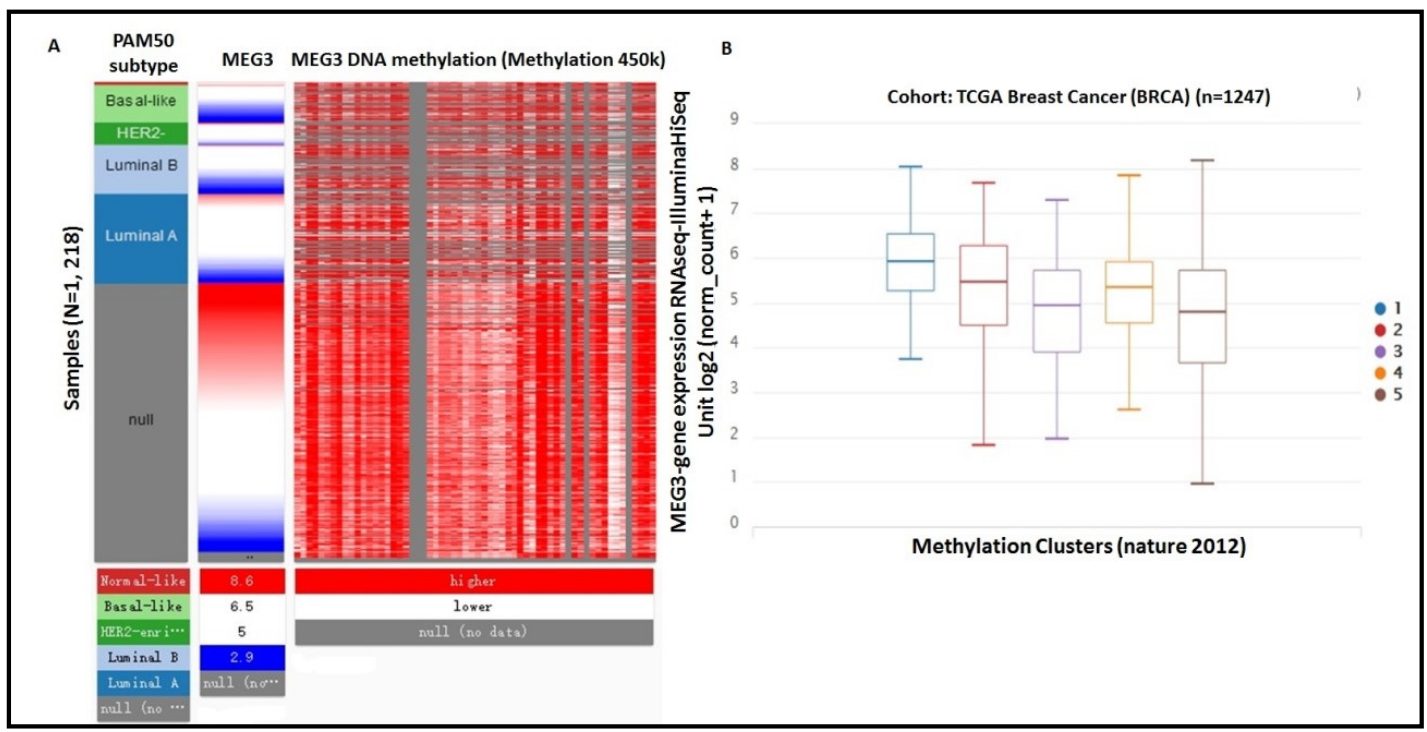

Fig. 4. A: Heat map of MEG3 expression and DNA methylation status; B: MEG3 expression in different breast cancer DNA methylation clusters. Results generated using the UCSC Xena browser based on data in TCGA.

where higher expression of MEG3 correlated with better overall survival (OS), relapse-free survival (RFS), distant metastasis-free survival (DMFS), and disease-specific survival (DSS) in breast cancer (Table 3, Fig. 6).

\section{Co-expression of MEG3 $m R N A$}

Co-expression of MEG3 was analyzed using Oncomine (Fig. 7A). The co-expression profile of MEG3 was identified with a large cluster of 3, 852 genes across 16 breast carcinomas (Fig. 7A) [34]. Heparan sulfate proteoglycan 2 (HSPG2) is a top correlated gene, which is underexpressed in breast cancer and inhibits chemotherapy resistance of breast cancer cells $[35,36]$. Data mining in bc-GenExMiner 4.0 confirmed a positive correlation between MEG3 and HSPG2 expression (Fig. 7B). We confirmed this positive correlation by analyzing breast cancer patient data in the TCGA database using UCSC Xena (http://xena.ucsc.edu/) (Fig. 7CD). These findings suggest that MEG3 might be closely related to the HSPG2 signaling pathway in breast cancer.
Table 2. The relationship between mRNA expression of MEG3 and clinicopathological parameters of breast carcinoma

\begin{tabular}{|c|c|c|c|}
\hline \multirow{2}{*}{ Variables } & \multicolumn{3}{|c|}{ MEG3 } \\
\hline & No.* & mRNA & $\mathrm{p}$-value \\
\hline \multicolumn{4}{|l|}{ Age } \\
\hline$\leq 51$ & 1392 & - & 0.6770 \\
\hline$>51$ & 2210 & - & \\
\hline \multicolumn{4}{|c|}{ Nodal Statas } \\
\hline - & 1896 & - & 0.8459 \\
\hline+ & 1017 & - & \\
\hline \multicolumn{4}{|l|}{ ER } \\
\hline - & 1197 & - & 0.0001 \\
\hline+ & 3177 & $\uparrow$ & \\
\hline \multicolumn{4}{|l|}{ PR } \\
\hline - & 733 & - & $<0.0001$ \\
\hline+ & 1173 & $\uparrow$ & \\
\hline \multicolumn{4}{|l|}{ HER2 } \\
\hline - & 1195 & - & 0.7568 \\
\hline+ & 166 & - & \\
\hline \multicolumn{4}{|c|}{ Basal-like Status } \\
\hline Not & 3322 & $\uparrow$ & $<0.0001$ \\
\hline Basal-like & 908 & - & \\
\hline \multicolumn{4}{|c|}{ Triple-negative Status } \\
\hline Not & 3254 & $\uparrow$ & 0.0056 \\
\hline TNBC & 293 & - & \\
\hline
\end{tabular}




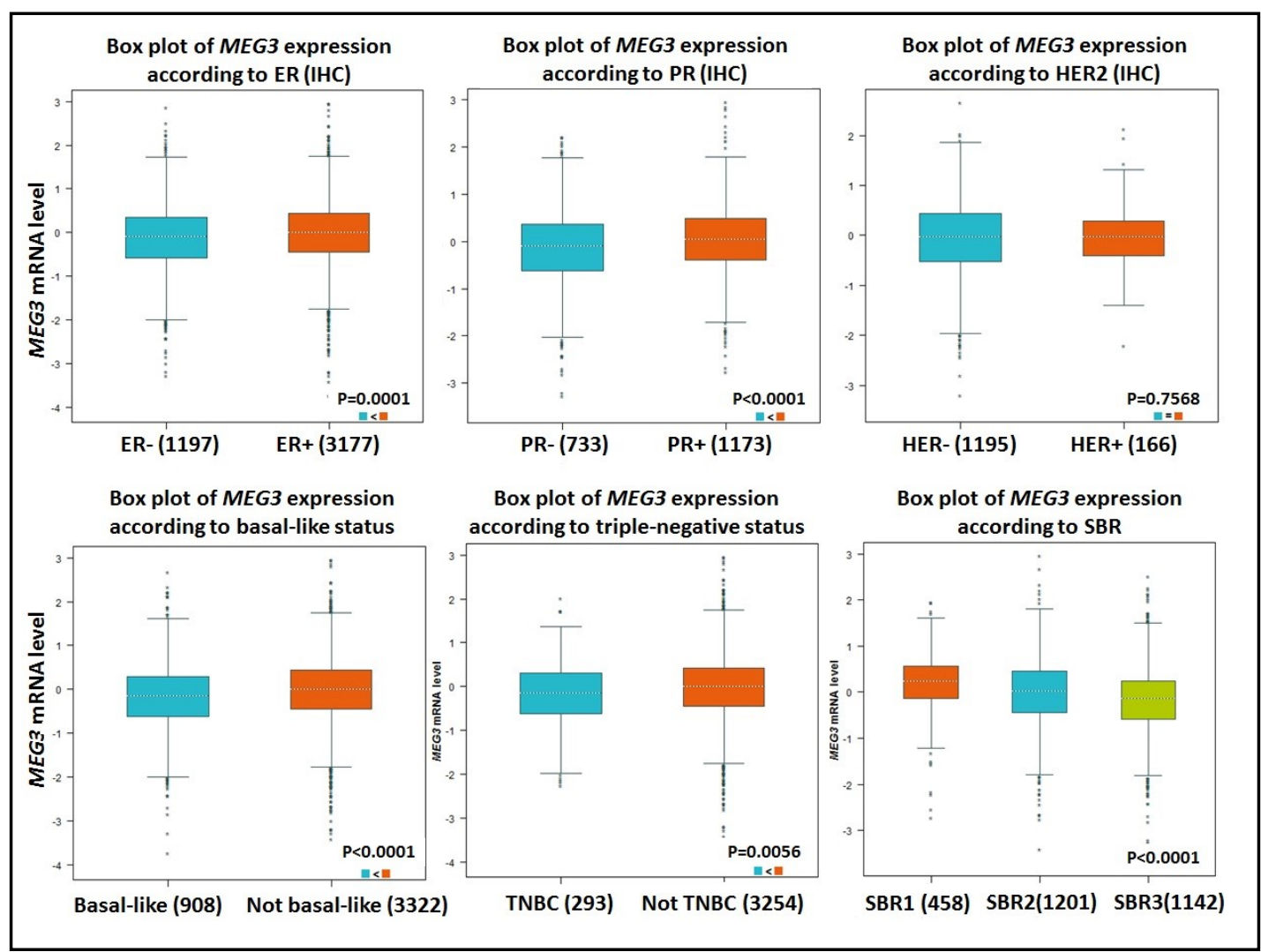

Fig. 5. Relationship between MEG3 expression and clinicopathological parameters in breast cancer patients. Global significant difference between groups was assessed by Welch's t-test to generate p values, along with Dunnett-Tukey-Kramer test.

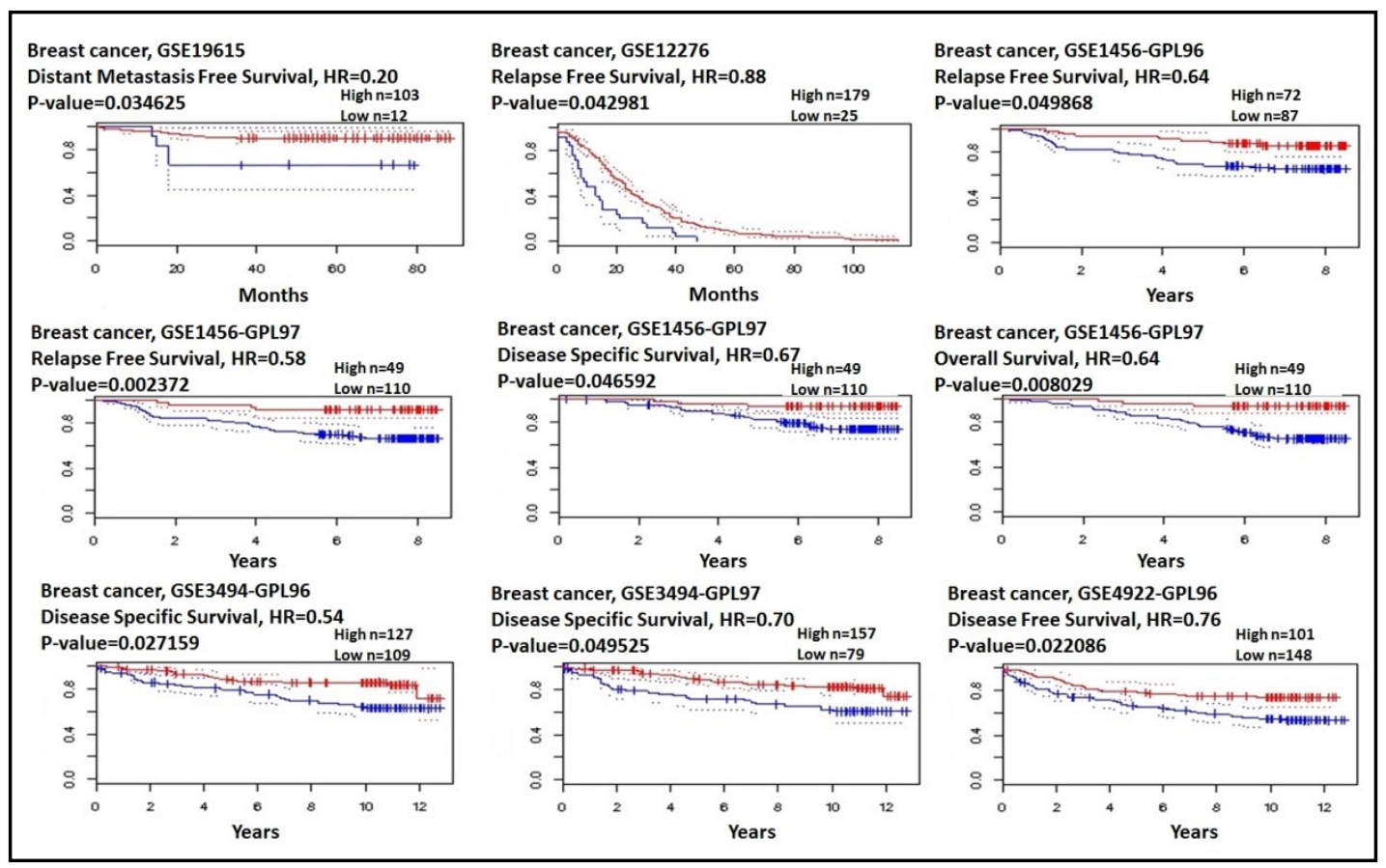

Fig. 6. Relationship between MEG3 expression and prognosis in breast cancer patients (PrognoScan database). Survival curve analysis with a threshold of $\mathrm{p}<0.05$ (Cox). 


\section{Discussion}

MEG3 is an imprinted gene within the DLK1-MEG3 locus located at human chromosome 14q32, which is the first IncRNA verified to act as a tumor suppressor and exert its anti-proliferative role through multiple signaling pathways $[16,17,37,38]$. Wei et al. have revealed that MEG3 can inhibit proliferation and metastasis of gastric cancer via the p53 signaling pathway [39]. Also, MEG3 inhibits proliferation and metastasis of oral squamous cell carcinoma by regulating the $\mathrm{WNT} / \beta$ catenin signaling pathway [23]. Overexpression of MEG3
Table 3. The association of MEG3 expression and the survival in breast cancer patients

\begin{tabular}{lccccc}
\hline DATASET & ENDPOINT & PROBE ID & N & COX P-VALUE & HR \\
\hline GSE19615 & Distant Metastasis Free Survival & 212732_at & 115 & 0.034625 & 0.20 \\
GSE12276 & Relapse Free Survival & 235077_at & 204 & 0.042981 & 0.88 \\
GSE1456-GPL96 & Relapse Free Survival & 212732_at & 159 & 0.049868 & 0.64 \\
GSE1456-GPL97 & Relapse Free Survival & 226210_s_at & 159 & 0.002372 & 0.58 \\
GSE1456-GPL97 & Disease Specific Survival & 226210_s_at & 159 & 0.046592 & 0.67 \\
GSE1456-GPL97 & Overall Survival & 226210_s_at & 159 & 0.008029 & 0.64 \\
GSE3494-GPL96 & Disease Specific Survival & 210794_s_at & 236 & 0.027159 & 0.54 \\
GSE3494-GPL97 & Disease Specific Survival & 226210_s_at & 236 & 0.049525 & 0.70 \\
GSE4922-GPL96 & Disease Free Survival & 212732_at & 249 & 0.022086 & 0.76 \\
\hline
\end{tabular}

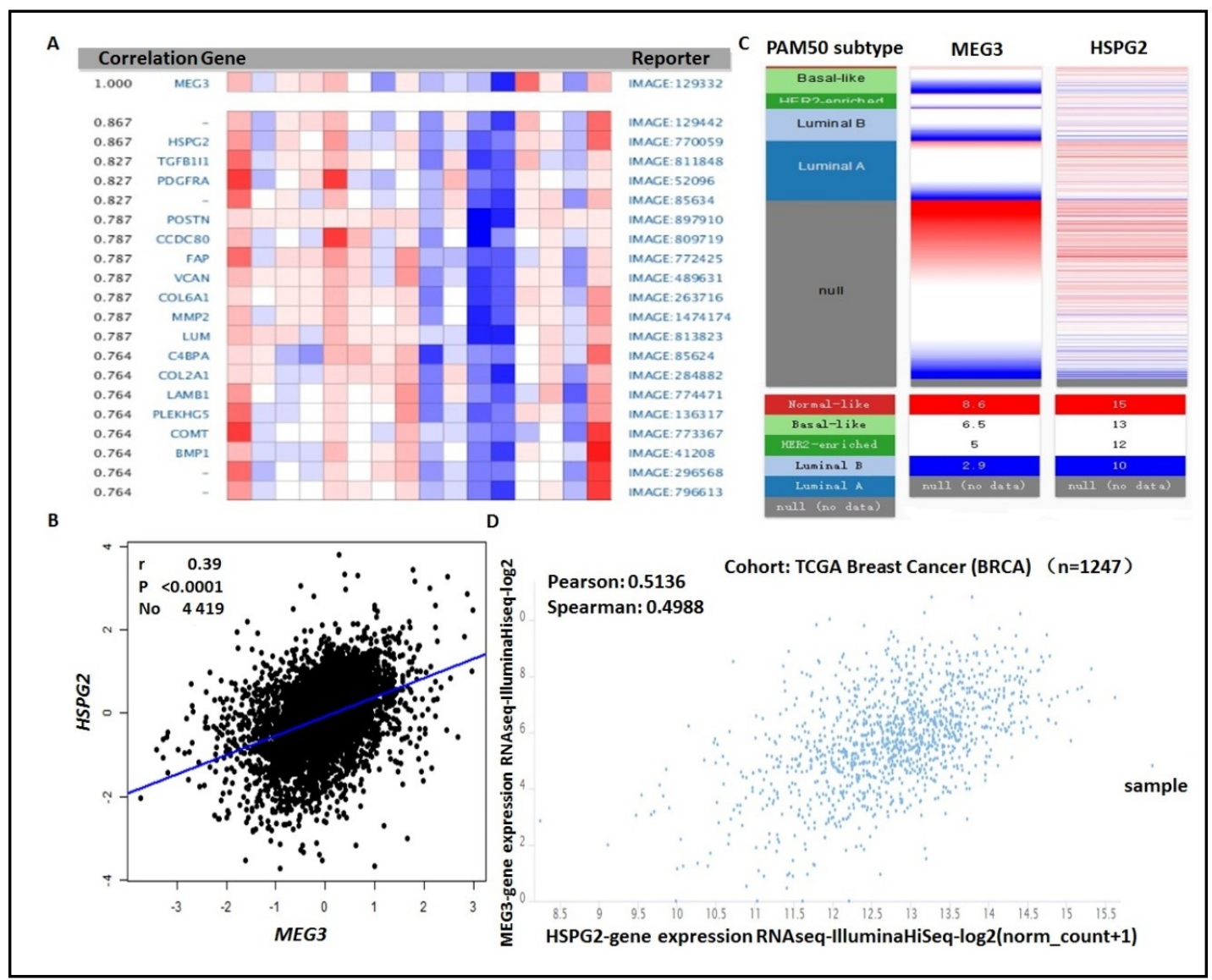

Fig. 7. A: MEG3 co-expression of genes analyzed using Oncomine. B: Relationship between MEG3 and HSPG2 in breast cancer analyzed using bc-GenExMiner v4.0; C: Heat map of MEG3 expression and HSPG2 mRNA expression across PAM50 breast cancer subtypes in the TCGA database, determined using UCSC Xena; D: Correlation between MEG3 and HSPG2 mRNA expression in the TCGA database, determined using UCSC Xena. 


\section{Cellular Physiology Cell Physiol Biochem 2018;50:41-51

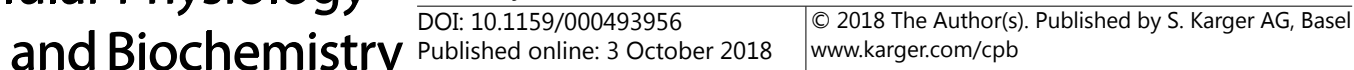 \\ Cui et al.: Mining Prognostic Significance of MEG3 in Human Breast Cancer}

can promote chemosensitivity of tumor cells through enhancing oxaliplatin-induced cell apoptosis [40]. However, the distinct role of MEG3 expression in the development and metastasis of breast cancer remains largely unknown.

To determine the role of MEG3 in the development, progression, and prognosis of breast cancer, we analyzed the data based on the level of gene expression with clearly defined parameters between cancer and normal tissues. Oncomine analysis revealed that MEG3 expression was significantly decreased in invasive breast carcinoma, invasive lobular breast carcinoma, invasive ductal breast carcinoma, male breast carcinoma, invasive ductal and lobular carcinoma, breast carcinoma, medullary breast carcinoma, mucinous breast carcinoma, ductal breast carcinoma in situ, and tubular breast carcinoma. Meanwhile, ER and PR status were found to be positively correlated with MEG3 expression. Conversely, basal-like status, TNBC status, and SBR criterion were negatively correlated with MEG3 expression. We further investigated the prognostic value of MEG3 in breast cancer using PrognoScan, and the pooled results revealed that low MEG3 expression correlated with shorter OS, RFS, DMFS, and DSS. Together, these findings indicate that decreased expression of MEG3 might be a useful marker of the prognosis of breast cancer.

Through co-expression and correlation analysis, we observed that HSPG2 was positively correlated with MEG3 expression. HSPG2 encodes for the perlecan protein, a large multidomain proteoglycan that cross-links extracellular matrix components and cellsurface molecules, which themselves play essential roles in multiple biological activities [41]. Hu et al. have demonstrated that overexpression of hypomethylated miR-663 might induce chemotherapy resistance in human breast cancer cells through targeting HSPG2 [35]. These previous findings and the present results together provide ample evidence that MEG3 expression might inhibit tumor migration and invasion associated with HSPG2 expression.

\section{Conclusion}

In summary, decreased expression of MEG3 was identified in breast cancer compared with matched normal tissues and is associated with the prognosis of breast cancer. HSPG2 could be adopted as a negative marker to predict the prognosis of breast cancer with MEG3. Large-scale and comprehensive studies are needed to confirm our findings and thus promote the clinical utility of MEG3 in the evaluation of breast cancer prognosis.

\section{Acknowledgements}

This study was supported by the Scientific Research Project of Shanxi Provincial Department of Health (grant no. 201601070) and Initial Scientific Research Fund of PhD in Shanxi Provincial People's Hospital (grant no. b201635

\section{Disclosure Statement}

The authors declare that no conflict of interest exists.

\section{References}

1 Lu X, Ma J, Chu J, Shao Q Zhang Y, Lu G, Li J, Huang X, Li W, Li Y, Ling Y, Zhao T: Mir-129-5p sensitizes the response of her-2 positive breast cancer to trastuzumab by reducing rps6. Cell Physiol Biochem 2017;44:2346-2356.

2 Yang C, Tabatabaei SN, Ruan X, Hardy P: The dual regulatory role of mir-181a in breast cancer. Cell Physiol Biochem 2017;44:843-856. 


\section{Cellular Physiology Cell Physiol Biochem 2018;50:41-51 \begin{tabular}{l|l|l} 
DOI: 10.1159/000493956 & (c) 2018 The Author(s). Published by S. Karger AG, Basel
\end{tabular} and Biochemistry

- Z Zou M, Li Y, Xia S, Chu Q, Xiao X, Qiu H, Chen Y, Zheng Z, Liu F, Zhuang L, Yu S: Knockdown of caveolin-1 sensitizes human basal-like triple-negative breast cancer cells to radiation. Cell Physiol Biochem 2017;44:778-791.

-4 Nielsen SM, White MG, Hong S, Aschebrook-Kilfoy B, Kaplan EL, Angelos P, Kulkarni SA, Olopade OI, Grogan RH: The breast-thyroid cancer link: A Syst Rev Meta-Analysis. The breast-thyroid cancer link: A systematic review and meta-analysis 2016;25:231-238.

5 Silvestri V, Rizzolo P, Zelli V, Valentini V, Zanna I, Bianchi S, Tibiletti MG, Varesco L, Russo A, Tommasi S, Coppa A, Capalbo C, Calistri D, Viel A, Cortesi L, Manoukian S, Bonanni B, Montagna M, Palli D, Radice P et al.: A possible role of fancm mutations in male breast cancer susceptibility: Results from a multicenter study in italy. Breast 2017;38:92-97.

6 Di Francia R, Atripaldi L, Di Martino S, Fierro C, Muto T, Crispo A, Rossetti S, Facchini G, Berretta M: Assessment of pharmacogenomic panel assay for prediction of taxane toxicities: Preliminary results. Front Pharmacol 2017;8:797.

7 Cui X, Jing X, Wu X: The prognostic value of long non coding rnas in cervical cancer: A meta-analysis. Oncotarget 2017;8:62470-62477.

8 Cui X, Jing X, Long C, Yi Q, Tian J, Zhu J: Accuracy of the urine uca1 for diagnosis of bladder cancer: A metaanalysis. Oncotarget 2017;8:35222-35233.

- Jing X, Liang H, Cui X, Han C, Hao C, Huo K: Long noncoding rna ccat2 can predict metastasis and a poor prognosis: A meta-analysis. Clin Chim Acta 2017;468:159-165.

10 Xu S, Wan L, Yin H, Xu H, Zheng W, Shen M, Zhang Z, Pang D: Long noncoding rna linc00152 functions as a tumor propellant in pan-cancer. Cell Physiol Biochem 2017;44:2476-2490.

-11 Jin F, Wang N, Zhu Y, You L, Wang L, De W, Tang W: Downregulation of long noncoding rna gas5 affects cell cycle and insulin secretion in mouse pancreatic beta cells. Cell Physiol Biochem 2017;43:2062-2073.

-12 Sui J, Yang X, Qi W, Guo K, Gao Z, Wang L, Sun D: Long non-coding rna linc-usp16 functions as a tumour suppressor in hepatocellular carcinoma by regulating pten expression. Cell Physiol Biochem 2017;44:1188-1198.

13 Wang J, Wang X, Chen T, Jiang L, Yang Q: Huaier extract inhibits breast cancer progression through a lncrna-h19/mir-675-5p pathway. Cell Physiol Biochem 2017;44:581-593.

14 Liu F, Dong Q, Huang J: Overexpression of lncrna pvt1 predicts advanced clinicopathological features and serves as an unfavorable risk factor for survival of patients with gastrointestinal cancers. Cell Physiol Biochem 2017;43:1077-1089.

15 Sun Z, Nie X, Sun S, Dong S, Yuan C, Li Y, Xiao B, Jie D, Liu Y: Long non-coding rna meg3 downregulation triggers human pulmonary artery smooth muscle cell proliferation and migration via the p53 signaling pathway. Cell Physiol Biochem 2017;42:2569-2581.

16 Cui X, Jing X, Long C, Tian J, Zhu J: Long noncoding rna meg3, a potential novel biomarker to predict the clinical outcome of cancer patients: A meta-analysis. Oncotarget 2017;8:19049-19056.

-17 Han L, Dong Z, Liu N, Xie F, Wang N: Maternally expressed gene 3 (meg3) enhances pc12 cell hypoxia injury by targeting mir-147. Cell Physiol Biochem 2017;43:2457-2469.

-18 Zhang J, Yao T, Wang Y, Yu J, Liu Y, Lin Z: Long noncoding rna meg3 is downregulated in cervical cancer and affects cell proliferation and apoptosis by regulating mir-21. Cancer Biol Ther 2016;17:104-113.

19 Gao Y, Huang P, Zhang J: Hypermethylation of meg3 promoter correlates with inactivation of meg3 and poor prognosis in patients with retinoblastoma. J Transl Med 2017;15:268.

20 Xiu YL, Sun KX, Chen X, Chen S, Zhao Y, Guo QG, Zong ZH: Upregulation of the lncrna meg3 induces autophagy to inhibit tumorigenesis and progression of epithelial ovarian carcinoma by regulating activity of atg3. Oncotarget 2017;8:31714-31725.

-21 Peng W, Si S, Zhang Q Li C, Zhao F, Wang F, Yu J, Ma R: Long non-coding rna meg3 functions as a competing endogenous rna to regulate gastric cancer progression. Journal of experimental \& clinical cancer research : CR 2015;34:79.

22 Yang NQ, Luo XJ, Zhang J, Wang GM, Guo JM: Crosstalk between meg3 and mir-1297 regulates growth of testicular germ cell tumor through pten/pi3k/akt pathway. Am J Transl Res 2016;8:1091-1099.

23 Liu Z, Wu C, Xie N, Wang P: Long non-coding rna meg3 inhibits the proliferation and metastasis of oral squamous cell carcinoma by regulating the wnt/beta-catenin signaling pathway. Oncology letters 2017;14:4053-4058. 


\section{Cellular Physiology Cell Physiol Biochem 2018;50:41-51

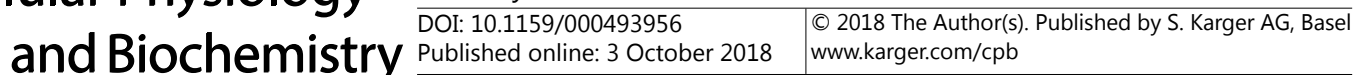

-24 Zhang L, Liang X, Li Y: Long non-coding rna meg3 inhibits cell growth of gliomas by targeting mir-93 and inactivating pi3k/akt pathway. Oncol Rep 2017;38:2408-2416.

25 Rhodes DR, Yu J, Shanker K, Deshpande N, Varambally R, Ghosh D, Barrette T, Pandey A, Chinnaiyan AM: Oncomine: A cancer microarray database and integrated data-mining platform. Neoplasia 2004;6:1-6.

-26 Li H, Chen C: Quercetin has antimetastatic effects on gastric cancer cells via the interruption of upa/ upar function by modulating nf-kappab, pkc-delta, erk1/2, and ampkalpha. Integr Cancer Ther 2017:1534735417696702.

27 Liakou E, Mavrogonatou E, Pratsinis H, Rizou S, Evangelou K, Panagiotou PN, Karamanos NK, Gorgoulis VG, Kletsas D: Ionizing radiation-mediated premature senescence and paracrine interactions with cancer cells enhance the expression of syndecan 1 in human breast stromal fibroblasts: The role of tgf-beta. Aging 2016;8:1650-1669.

28 Chen D, Zou J, Zong Y, Meng H, An G, Yang L: Anti-human cd138 monoclonal antibodies and their bispecific formats: Generation and characterization. Immunopharmacol Immunotoxicol 2016;38:175-183.

29 Jezequel P, Campone M, Gouraud W, Guerin-Charbonnel C, Leux C, Ricolleau G, Campion L: Bc-genexminer: An easy-to-use online platform for gene prognostic analyses in breast cancer. Breast Cancer Res Treat 2012;131:765-775.

-30 Jezequel P, Frenel JS, Campion L, Guerin-Charbonnel C, Gouraud W, Ricolleau G, Campone M: Bc-genexminer 3.0: New mining module computes breast cancer gene expression correlation analyses. Database 2013;2013:bas060.

31 Mizuno H, Kitada K, Nakai K, Sarai A: Prognoscan: A new database for meta-analysis of the prognostic value of genes. BMC Med Genomics 2009;2:18.

32 Gluck S, Ross JS, Royce M, McKenna EF, Jr., Perou CM, Avisar E, Wu L: Tp53 genomics predict higher clinical and pathologic tumor response in operable early-stage breast cancer treated with docetaxel-capecitabine +/- trastuzumab. Breast Cancer Res Treat 2012;132:781-791.

-33 Curtis C, Shah SP, Chin SF, Turashvili G, Rueda OM, Dunning MJ, Speed D, Lynch AG, Samarajiwa S, Yuan Y, Graf S, Ha G, Haffari G, Bashashati A, Russell R, McKinney S, Group M, Langerod A, Green A, Provenzano E et al.: The genomic and transcriptomic architecture of 2, 000 breast tumours reveals novel subgroups. Nature 2012;486:346-352.

-34 Hedenfalk I, Ringner M, Ben-Dor A, Yakhini Z, Chen Y, Chebil G, Ach R, Loman N, Olsson H, Meltzer P, Borg A, Trent J: Molecular classification of familial non-brca1/brca2 breast cancer. Proc Natl Acad Sci U S A 2003;100:2532-2537.

35 Hu H, Li S, Cui X, Lv X, Jiao Y, Yu F, Yao H, Song E, Chen Y, Wang M, Lin L: The overexpression of hypomethylated mir-663 induces chemotherapy resistance in human breast cancer cells by targeting heparin sulfate proteoglycan 2 (hspg2). J Biol Chem 2013;288:10973-10985.

-36 Valladares A, Hernandez NG, Gomez FS, Curiel-Quezada E, Madrigal-Bujaidar E, Vergara MD, Martinez MS, Arenas Aranda DJ: Genetic expression profiles and chromosomal alterations in sporadic breast cancer in mexican women. Cancer Genet Cytogenet 2006;170:147-151.

-37 Zhang YY, Feng HM: Meg3 suppresses human pancreatic neuroendocrine tumor cells growth and metastasis by down-regulation of mir-183. Cell Physiol Biochem 2017;44:345-356.

-38 Wang N, Zhu Y, Xie M, Wang L, Jin F, Li Y, Yuan Q De W: Long noncoding rna meg3 regulates mafa expression in mouse beta cells by inactivating rad21, smc3 or sin3alpha. Cell Physiol Biochem 2018;45:2031-2043.

39 Wei GH, Wang X: Lncrna meg3 inhibit proliferation and metastasis of gastric cancer via p53 signaling pathway. Eur Rev Med Pharmacol Sci 2017;21:3850-3856.

40 Li L, Shang J, Zhang Y, Liu S, Peng Y, Zhou Z, Pan H, Wang X, Chen L, Zhao Q: Meg3 is a prognostic factor for crc and promotes chemosensitivity by enhancing oxaliplatin-induced cell apoptosis. Oncol Rep 2017;38:1383-1392.

41 Basit S, Albalawi AM, Alharby E, Khoshhal KI: Exome sequencing identified rare variants in genes hspg2 and atp2b4 in a family segregating developmental dysplasia of the hip. BMC Med Genet 2017;18:34. 